\title{
Evaluate the influence of starch on earth/hemp or flax straws mixtures properties in presence of superplasticizer
}

\author{
Ghaith Alhaik $^{\mathrm{a}, *}$, Vincent Dubois ${ }^{\mathrm{b}}$, Eric Wirquin $^{\mathrm{b}}$, Alexandre Leblanc ${ }^{\mathrm{b}}$, \\ Georges Aouad ${ }^{c}$ \\ ${ }^{a}$ University of Cergy-Pontoise, 5 Mail Gay Lussac, 95031 Neuville-sur-Oise, France \\ ${ }^{b}$ Univ. Artois, EA 4515, Laboratoire de Génie Civil et géo-Environnement ( $L G C g E$ ), \\ F-62400 Béthune, France \\ ${ }^{c}$ Faculty of Engineering, University Of Balamand, UOB, Al Koura, Lebanon
}

\begin{abstract}
In this paper, we study the influence of two types of starch on earth hemp or flax straw mixtures at fresh and hardened states. The main goal is to propose new non-load bearing earthen for indoor. The mass percentage of starch/binder $(\mathrm{S} / \mathrm{B})$ in mixtures was fixed at $1 \%$ of mass. The VEBE consistometer test has been used to fix a similar consistency between mixtures. The targeted workability has to allow an easy introduction of materials in the moulds. Adding both of starch has shown a positive effect on mixtures workability at the fresh state and mechanical resistances at the hardened state. At hardened state, mechanical and thermal-acoustic performances have been measured on laboratory samples and blocks at real scale. Results have shown a significant effect of starch on mechanical strengths.
\end{abstract}

Keywords: Starch, Earth/straw blocks, Mechanical performances

\footnotetext{
${ }^{*}$ Corresponding author: ghaith.alhaik.84@hotmail.com
} 


\section{INTRODUCTION}

Currently, the return to more ecological values largely favours the renewed interest in sustainable and economical building materials such as Raw Earth Materials (REMs). REMs, used as building materials in a quarter of the world's

5 dwellings and in more than a third of world heritage monuments, represent an interesting solution for ecological problems because it's a local resource and needs a little energy for its implementation. In addition, REMs give to walls properties of comfort in accordance with the criteria requested by the French current thermal regulations RT 2012. Indeed, REMs allow a regulation of the humidity in the rooms. It can also regulate the temperature due to its inertia and thus bring, in particular, summer comfort by phase shift. The hygrothermal regulation capacity and the limitation of energy consumption and greenhouse gas emissions during the manufacture and the implementation of this type of products are major advantages in comparison with existing conventional products. Often associated with straw, a light material is obtained with interesting performances for thermal and acoustic insulation. REMs-straw association represents a way of using the REMs spread geographically for centuries. But ancestral practices are opposed to current industrial practices because of the long time needed to set up and dry these mixes, which must be moistened in order to work with the straw.

Nowadays the objective is to be able to build quickly and well. REMs-straw mixes can be developed and adapted to fit into a conventional distribution circuit where most building materials are purchased. In the past three decades, considerable efforts have been directed towards the use of various plant fibers, which are abundantly available in tropical and subtropical countries, for the production of cost-effective building materials for sustainable development. The earth-straw products must thus meet the constraints of prefabrication and short 
storage to be competitive in comparison with concrete or gypsum products. The handling of the material in the fresh state must be easier and the mechanical performance must be improved, while keeping the environmental benefits. Several investigations have been dedicated on the study of earth-straw mixtures to find the best mechanical and thermal properties of products made with unfired earth, stabilized or unstabilized. Dubois et al [1] have studied the association of quarry fines-hemp to be used in the manufacture of precast non-bearing products. Brouard et al 2] have compared two types of vegetable aggregates (rape straw and sunflower) associated with earth in order to study mechanical and hygrothermal behavior of plaster bio-composite. While Degrave-Lemeurs et al [3] have studied and compared acoustical properties of hemp-clay samples with hemp-lime ones. Laborel-Préneron et al have written a review on the use of 40 plant aggregates and fibers in earth construction materials [4]. Other research studies have studied the association of clay-hemp [5], clayey soil-nature fibre [6], clay-straw [7, 8, clay-wheat straw $9,10,11$. All these research works showed the benefits by associating the earth with plant aggregates especially to enhance the insulation performances.

${ }_{45}$ Furthermore, with the environmental problems, researchers are focusing on renewable and bio-based resources to reduce the environmental impacts of building materials, which in turn promotes the development of eco-building materials. Thus the civil engineering is today in connection with the field of green chemistry, which develops bio-based additives made of plant origin such as the family of polysaccharides. Several research studies have outlined the benefits of using starch on construction. Starch is a homopolymer from polysaccharides family with $100 \%$ vegetable origin. It exists in several vegetables like tubers, cereals and legumes. Starch is composed principally of amylose and amylopectin, in addition of minor percentages of protein, lipids and phosphorus. It could be dif- 
ferentiated from other polysaccharides because of its amylopectin which has a strong influence on the dispersion and stabilization of particles [12]. A.T. Le et al [13, 14] have replaced, in the composition of hemp concrete, lime by starch to obtain a lighter dry density (between 170.8 and $158.9 \mathrm{~kg} / \mathrm{m}^{3}$ ), with satisfactory compressive strength (between 0.4 and $0.5 \mathrm{MPa}$ ), knowing that for hemp concrete, the average of compressive strength varies from 0.1 to $0.8 \mathrm{MPa}$ for a dry density between 330 and $470 \mathrm{~kg} / \mathrm{m}^{3}$. They also showed up that starch/hemp cannot be used as a construction material because of their very low Young's modulus (between 1.47 and $2.16 \mathrm{MPa}$ ) for these range of densities. Akindehinde et al [15] have studied the influence of two types of starch (maize and cassava) on certain properties of concrete. The results of the mechanical tests up to 180 days of cure showed that both starches have a positive impact on the concrete especially in the short term (up to 28 days): for example, adding $1 \%$ of starch by weight of cement gave an increase of $5.3 \%$ and $4,9 \%$ the compressive strengths with corn and cassava starch, respectively. On the other hand, increasing the percentage of starch from $1 \%$ to $1.5 \%$ or even $2 \%$ has a less important or even negative effect from 28 days of treatment. Other studies show that the addition of starch improves the workability of cement pastes and can be used as a replacement for petrochemical adjuvants reducing water [16]. In previous research work, Alhaik et al [17] showed that starch improves the mechanical strengths of clayey materials. The addition of starch has also increased the thixotropic index up to four times. This study comes as a continuing of previous research work [17, which had shown that starches have a very important effect on the rheological and mechanical properties of earth paste. Therefore, the main goal of the present work is to evaluate the influence of two types of starch on earth/plant mixtures at fresh and hardened states. 


\section{MATERIALS}

In this section, the characteristics of materials used in this work are shown.

\subsection{Quarry fines $(Q F)$}

Earth materials used in this work are quarry fines furnished by "Carrières 85 du Boulonnais", which is a company located in the north of France. These quarry fines come as a result of aggregates washed in the quarry to respect the European standard EN 12620 [18]. The analysis by X-ray diffraction according to the European standard EN 13925-2 [19] carried out by the company "Carrières du Boulonnais" has shown a majority of limestone and clay. There-

90 fore, these materials are defined as Ap (low plastic clay) according to the USCS classification. Table 1 presents the properties of the quarry fines measured by Carrières du Boulonnais. Despite a relatively small proportion of clay in these materials (19\%), they present physical behavior of clay. The clay part is composed of kaolinite $(12 \%)$ and illite $(7 \%)$, which have low sensitivity to swelling 95 phenomena.

\begin{tabular}{|c|c|}
\hline Properties & Values \\
\hline Proctor test & \\
\hline Optimum moisture content & $14 \%$ \\
\hline Maximum dry density & $1860 \mathrm{~kg} / \mathrm{m}^{3}$ \\
\hline \multicolumn{2}{|l|}{ Atterberg limits } \\
\hline Liquid limit LL & $33 \%$ \\
\hline Plastic limit PL & $21 \%$ \\
\hline Plasticity index PI & $12 \%$ \\
\hline \multicolumn{2}{|c|}{ Particle size distribution } \\
\hline Sand $(2-0.063 \mathrm{~mm})$ & $1.5 \%$ \\
\hline Silt $(0.075-0.002 \mathrm{~mm})$ & $81.3 \%$ \\
\hline Clay $(<0.002 \mathrm{~mm})$ & $17.2 \%$ \\
\hline Organic content & $2.17 \%$ \\
\hline
\end{tabular}

The granular distribution of QF performed by the laser diffraction methods 
[19] shows that these quarry fines have grain sizes ranging from 0.1 to $100 \mu \mathrm{m}$, with dominant sizes $(60 \%)$ between 0.1 to $20 \mu \mathrm{m}$.

\subsection{Starch}

The starch used in this study has grains sizes of 1-100 $\mu \mathrm{m}$ in the form of a white powder. Starches vary in size and shape according to theirs botanical origins [20]. Based on the results of previous research work [17], two starches (D and $\mathrm{H}$ ) have been chosen for this study, according to their efficiency to improve both of rheological and mechanical proprieties. The first starch (mentioned D) is a native starch while the other one (mentioned $\mathrm{H}$ ) is a pregelatinized starch which had been cooked in hot water according to its gelling temperature. During the process of gelatinization, particles of starch lose their semi crystalline structure then they change their viscosity according to their vegetable origin as well as their percentage of amylose and amylopectin. This process is irreversible and gives a soluble starch (about 98\%) in water at ambient temperature. Both of starches were prepared and furnished by Roquette which is a company specialized in the starches production.

\subsection{Hemp and flax straws}

Two by-products "hemp and flax straws" have been chosen for this study. Their apparent densities, measured in laboratory, are $121.2 \mathrm{~kg} / \mathrm{m}^{3}$ and 105.8 $\mathrm{kg} / \mathrm{m}^{3}$ for hemp and flax straw, respectively. Figure 1 shows the particles observations of hemp and flax straws. The maximum size of hemp or flax straw particles is up to $40 \mathrm{~mm}$. Hemp and flax straws have a high porosity and their porosity induces a large and fast water absorption, with water absorption of 130\% (mass ratio water/dry straw) one minute after immersion (Fig. 2). All of these measurements have been done according to the recommendation of the RILEM TC 236-BBM [21]. The optical image of both of plant aggregates 
presented in figure 1 shows the small diamter of flax particles compared to hemp particles diamter.

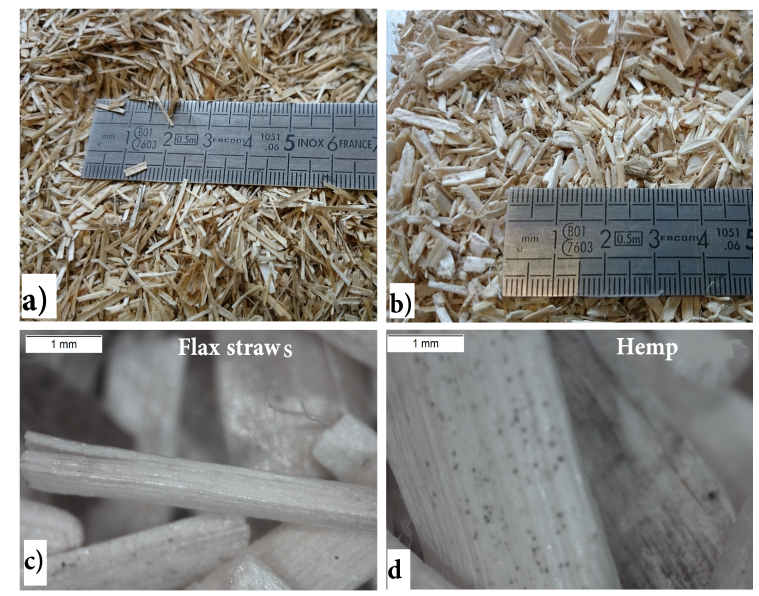

Figure 1: Macro and Micro observations of particles of flax straws(left) and hemp (right).

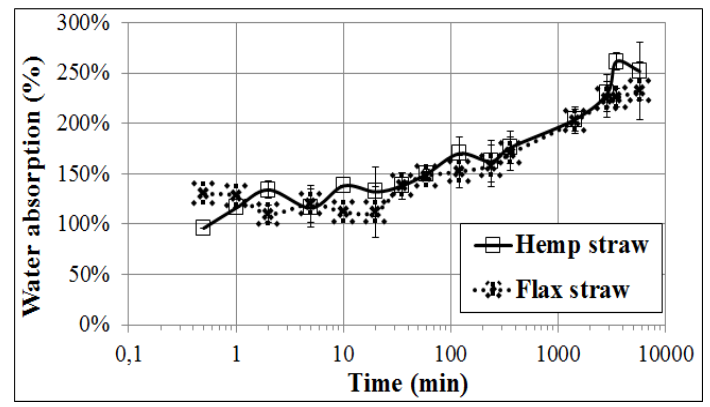

Figure 2: Water absorption of hemp and flax straw.

\subsection{Superplasticizer (SP)}

The superplasticizer Chryso Fluid Premia 205 (SP) has been chosen for this study. This superplasticizer was used by Dubois et al [1] to reduce the water content in $\mathrm{QF} /$ hemp mixtures. In this study, the same superplasticizer (dry extract)/binder (SP/B) ratio of $1.3 \%$ is chosen. This superplasticizer is ${ }_{130}$ furnished at liquid state with a dry extract of $30.3 \%$ and a density equal to 1.055 . 
It is incorporated with water during the mixing. The letters (SP) indicate that mixtures include a superplasticizer.

\subsection{Lime $(L)$}

The commercial name of the lime (L) used in this study is AKTA Chaux.

It is composed of natural hydraulic lime, natural pozzolans, clinker, limestone fillers and admixtures.

\section{METHODOLOGY}

\subsection{Mixtures parameters}

The term binder, in this study corresponds to the mineral part whereas the term of aggregate to hemp or flax straw. Two binder/aggregate ratios (B/A) have been chosen equal to 5.5 or $3.5 \%$ and a starch/binder ratio (S/B) equal to $1 \%$, respectively. The water/binder ratio $(\mathrm{W} / \mathrm{B})$ has been fixed experimentaly to obtain the same workability for all mixtures. In this work, each mixture had been referenced with numbers and letters which correspond to:

- For the two first numerals to the $\mathrm{B} / \mathrm{A}$ ratio without decimal point,

- For the two following numerals to the W/B ratio without decimal point,

- For the letter $\mathrm{D}$ or $\mathrm{H}$ to the type of starch,

- For letters SP to the presence of superplasticizer,

- For the letter L to the presence of lime,

- For the mixtures with flax straw, the letter F was added at the end. For the others references, hemp straw has been used.

For example, the $(5506 \mathrm{D})$ mixture means that $\mathrm{B} / \mathrm{A}$ ratio is $5.5, \mathrm{~W} / \mathrm{B}$ ratio is 0.6, the letter D corresponds to type of starch used in this mixture and hemp 
straw for vegetal part.

155 The dry density has been fixed to $800 \pm 100 \mathrm{~kg} / \mathrm{m}^{3}$ in order to obtain a maximum mass of block of $20 \mathrm{~kg}$ to easily handle the products on building sites. The weight of each component in the mixture have been obtained by equations 1 to 6 .

$$
\begin{gathered}
\text { Dry density }=\frac{M_{\text {binder }}+M_{\text {aggregate }}+M_{\text {starch }}}{V} \\
M_{\text {binder }}=M_{Q F}+M_{\text {Lime }}
\end{gathered}
$$

$$
\begin{gathered}
M_{\text {starch }}=1 \% \times M_{\text {binder }} \\
\text { Two B } / A \text { ratio }: \quad \frac{M_{\text {binder }}}{M_{\text {aggregate }}}=5.5 \text { or } 3.5 \\
W / B=M_{\text {water }} / M_{\text {binder }} \\
M_{S P}=1.3 \% \times M_{\text {binder }}
\end{gathered}
$$

\subsection{Mixing procedures}

A planetary concrete mixer was chosen in this study to prepare the materials. Pregelatinized starch $(\mathrm{H})$ included in some mixtures is cold water-soluble, whereas the native one (D) chosen for this experimental campaign needs hot water for gelatinization. Three mixing procedures have been designed inspired from the EN 196-1 standard [22]: one for the reference mixtures (without starch) and the other two for mixtures (including both of starches $\mathrm{D}$ or $\mathrm{H}$ ).

The first procedure for reference mixtures was as the following:

1) Put all water in the mixer,

2) Add progressively of QF (60 s) then mixing (60 s),

3) Add progressively of the hemps or flax straw (60 s) then mixing(60s),

4) Scraping the bowl (30 s - stop) then mixing (30 s). 
The second procedure for cold mixtures was as the following:

1) Mixing starch $\mathrm{H}$ with $\mathrm{QF}$,

2) Put all water in the mixer,

3) Add progressively of QF/starch $\mathrm{H}$ (60 s) then mixing (60 s),

4) Add progressively of the hemps or flax straw (60 s) then mixing(60 s),

5) Scraping the bowl (30 s - stop) then mixing (30 s).

The third procedure for warm mixtures was as the following:

1) Divide the amount of water in two parts (90\% hot and $10 \%$ cold)

2) Mixing cold water+starch D until homogeneity (to obtain starch milk)

3) Mixing the starch milk with hot water then put the whole in the mixer

4) Add progressively of QF (60 s) then mixing (60 s),

5) Add progressively of the hemps or flax straw (60 s) then mixing(60 s),

6) Scraping the bowl (30 s - stop) then mixing (30s).

For mixtures including superplasticizer and/or lime, the superplasticizer was

190 with QF.

\subsection{Evaluate mixtures consistencies}

A VEBE consistometer has been used to evaluate the consistency of mixtures according to the standard EN 12350-3 [23]. The VEBE consistometer is usually used to evaluate the concrete consistency with a spreading time between (5 - $30 \mathrm{~s})$. Based on preliminary tests [1], the spreading time has been adapted 
with these mixtures.

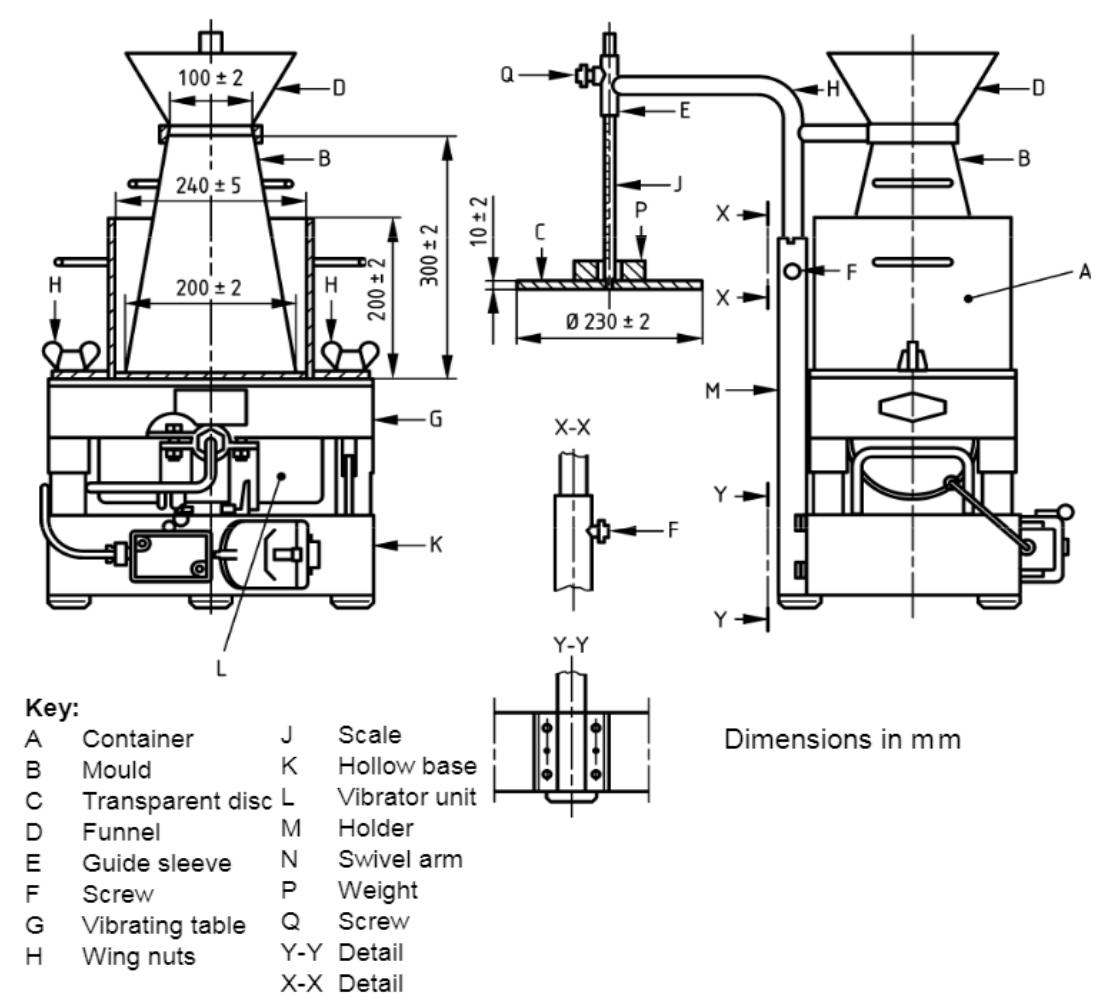

Figure 3: Typical Consistometer (Vebe meter) 23.

As illustrated in the figure 3 the VEBE consistometer is made of a metallic cylinder $(d=240 \mathrm{~mm}, h=200 \mathrm{~mm})$, a tronconic mold and a transparent horizontal disc $(d=230 \mathrm{~mm})$ fixed on a metal graduated ruler. All these elements are placed on a vibrating table which produces 3000 vibrations per minute that cause movements with vertical amplitude about $0.5 \mathrm{~mm}$. The tronconic mold is filled with the material in three layers. Each layer is tamped 25 times with a metal rod measuring $(l=600 \mathrm{~mm}, \phi=16 \mathrm{~mm})$. Then the mold is pulled and the transparent disc is placed on the top of the material. The vibrating table is launched at the same time as a chronometer. The vibrations cause the material 
to sag and to gradually come into contact with the disc. When the material touches the whole disc, the chronometer is stopped and the time corresponds to

\subsection{Mechanical tests}

\subsubsection{Casting protocol}

The wet mass of matter to fill in the molds is chosen to respect the targeted dry density of $800 \mathrm{~kg} / \mathrm{m}^{3}$. The small diameter for flax straw prticles caused an the impossibility to ensure a $100 \%$ homogeneous implementation. Consequently, two dry density of $800 \pm 100 \mathrm{~kg} / \mathrm{m}^{3}$ and $900 \pm 100 \mathrm{~kg} / \mathrm{m}^{3}$ have been chosen for mixtures with hemp straw and flax straw, respectively. The mixture was put in the mold in two layers, each layer is compacted with 15 uniformly distributed chanical tests are performed, in the laboratory with conditions of $20^{\circ} \mathrm{C}$ and $50 \%$ RH. These conditions are similar to conditions of storage after manufacturing or to inner ambiance in a building. A USB data logger (EL-USB-2) had been used to verify the temperature and the humidity in the laboratory room. During the the mechanical tests. With the same protocol, blocks of $7 \times 50 \times 65 \mathrm{~cm}^{3}$ have been manufactured with the compositions having the best results in laboratory specimens in order to verify and validate these results. All blocks are immediately demoulded and stored under the same conditions of $20^{\circ} \mathrm{C}$ and $50 \% \mathrm{RH}$ for 230

\subsubsection{Operating mode for mechanical tests}

An electromechanical testing machine has been used to measure the mechanical strengths. This machine has a force capacity of $50 \mathrm{kN}$ and ensures a 
satisfactory level of precision $( \pm 0.5 \%$ between 0 and $0.5 \mathrm{kN}$ and $\pm 0.3 \%$ between

$0.5 \mathrm{kN}$ and $50 \mathrm{kN}$ ) for the non-bearing products. The mechanical tests have been done 28 days after manufacturing on the prismatic specimens of $7 \times 7 \times 28$ $\mathrm{cm}^{3}$ according to the EN 12390-5 standard 24].

The three-point bending tests are carried out according to the EN 12859 standard 25$]$ in a similar way as the gypsum blocks. The length between bottom supports is $566 \mathrm{~mm}$ for blocks (Fig 4 ).

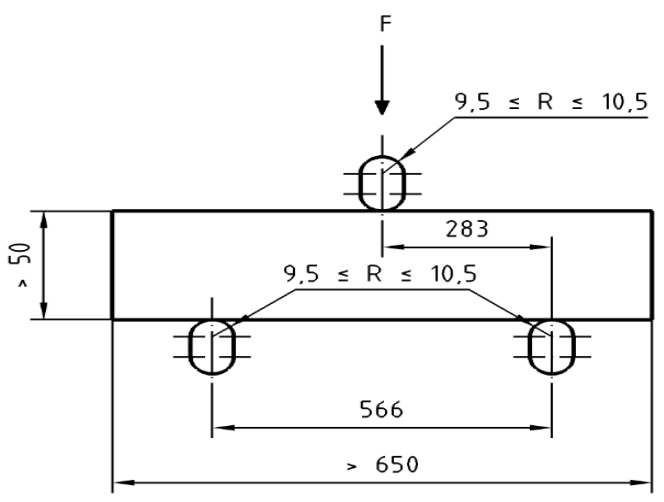

Figure 4: Bending strength testing device for blocks [25].

A constant loading rate of $4 \mathrm{~N} / \mathrm{sec}$ had been chosen for flexural strengths on laboratory samples. For blocks, a constant loading rate of $20 \mathrm{~N} / \mathrm{sec}$ had been chosen for flexural strengths based on french norme recommandations [25]. Whereas, a constant displacement rate of $1 \mathrm{~mm} / \mathrm{min}$ upon $30 \mathrm{~N}$ puis $5 \mathrm{~mm} / \mathrm{min}$ was applied on the half-blocks obtained after flexural test. This value was chosen according to the work of Flament [26] and Cerezo [27.

\subsection{Thermal and acoustic characteristics}

For thermal measurement, a guarded hot plate with two fluxmeters having a circular form $(\mathrm{D}=8 \mathrm{~cm})$ is used. Two parameters have been measured thermal 
conductivity $(\lambda)$ and mass heat capacity $(\mathrm{C})$ according to EN 12667 standard [28. The sample is placed between two plates. For the thermal conductivity measurement, one plate is at $15^{\circ} \mathrm{C}$ and the other one at $25^{\circ} \mathrm{C}$. For the mass heat transfer, plates are initially at $15^{\circ} \mathrm{C}$ then the temperature is increased to $25^{\circ} \mathrm{C}$. Two prism samples of $\left(25 \times 25 \times 7 \mathrm{~cm}^{3}\right)$ per type of product are tested, with similar composition with that of blocks for mechanical tests.

To measure the acoustic measurement, the impedance tube is used according to the EN ISO 10534-1 standard [29]. For this test, two cylindrical samples per formulation have been manufactured $(D=10 \mathrm{~cm}, h=7 \mathrm{~cm})$. The test sample is put on one end of a straight impedance tube that is rigid, smooth and airtight. Plane waves are generated in the tube by a sound source and the sound pressures are measured at two locations near the sample. The complex acoustic transfer function of the two microphone signals is determined and used to calculate the normal incidence absorption factor. The thermal and acoustic results are compared with performances of conventional products.

\section{RESULTS AND DISCUSSION}

\subsection{At fresh state}

\subsubsection{Influence of starch on $Q F /$ hemp or flax straw mixtures consistency}

Several mixtures have been tested (Tab. 2 in order to determinate the influence of water content as well as the influence of starch on $\mathrm{QF} /$ hemp or flax straw consistency. Results presented on figure 5 show that:

Table 2: Studied mixtures.

\begin{tabular}{l|ccccccc}
\hline With hemp & 5506 & 5507 & 5508 & $5509 \mathrm{D}$ & $5510 \mathrm{D}$ & $5509 \mathrm{H}$ & $5510 \mathrm{H}$ \\
With flax & $5506-\mathrm{F}$ & $5507-\mathrm{F}$ & $5508-\mathrm{F}$ & $5509 \mathrm{D}-\mathrm{F}$ & $5510 \mathrm{D}-\mathrm{F}$ & $5509 \mathrm{H}-\mathrm{F}$ & $5510 \mathrm{H}-\mathrm{F}$ \\
\hline
\end{tabular}


- In $\mathrm{QF} /$ hemp mixtures, increase the $\mathrm{W} / \mathrm{B}$ ratio from 0.6 to 0.7 makes it possible to have a measurable filling time.

- In $\mathrm{QF} /$ flax mixtures, $\mathrm{W} / \mathrm{B}$ ratio has to be increased to 0.8 to obtain a measurable filling time.

- The addition of starch on $\mathrm{QF} /$ hemp or flax straw mixtures causes a large increase of W/B ratio for the same consistency which had been confirmed in in previous research work conducted in the laboratory [17.

The difference between $\mathrm{W} / \mathrm{B}$ ratio for $\mathrm{QF} /$ hemp or $\mathrm{QF} /$ flax mixtures at the same consistency could be linked to the small particles diameter of flax straw.

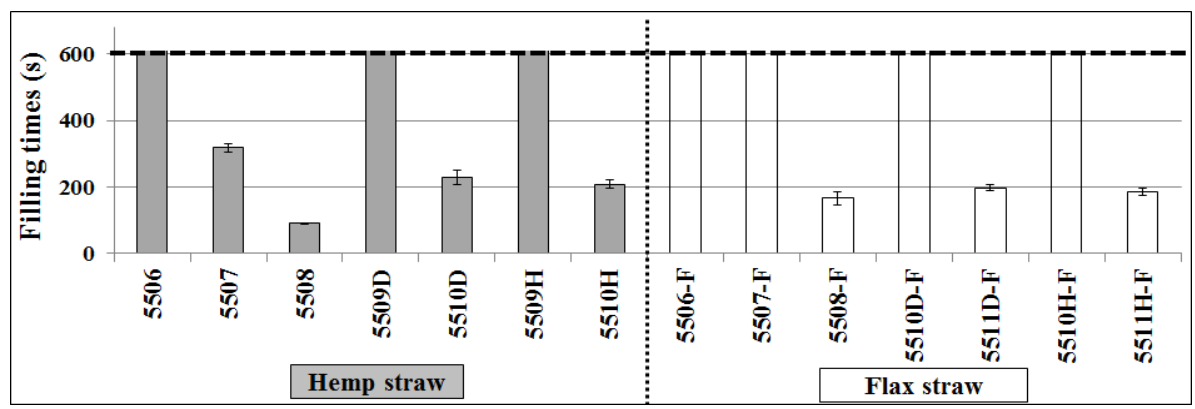

Figure 5: Filling times with VEBE consistometer for studied mixtures.

Studied mixtures have been classed in two groups: first group for mixtures with filling time higher than 600s and the other one for mixtures with filling time smaller than 600s. The choice was to work with mixtures which had filling time higher than 600s. This choice allows an immediate unmolding after casting. Therefore, the $\mathrm{W} / \mathrm{B}$ ratio chosen is 0.6 .

Despite this choice, manufacturing specimens with mixtures including starch was impossible while respecting the density referred to because of their high water content. Adding a superplasticizer was the best solution to decrease the water content in mixtures. 


\subsubsection{Influence of superplasticizer's addition}

Figure 6 shows the comparison of the filling times for mixtures with and without superplasticizer including hemp straw (left) or flax straw (right). The capacity of superplasticizer to reduce the W/B ratio is clearly highlighted for the same consistency of mixture. Adding $1.3 \%$ of superplasticizer induce a decrease about of $30 \%$ and $35 \%$ of water content for mixtures including hemp or flax straw, respectively.
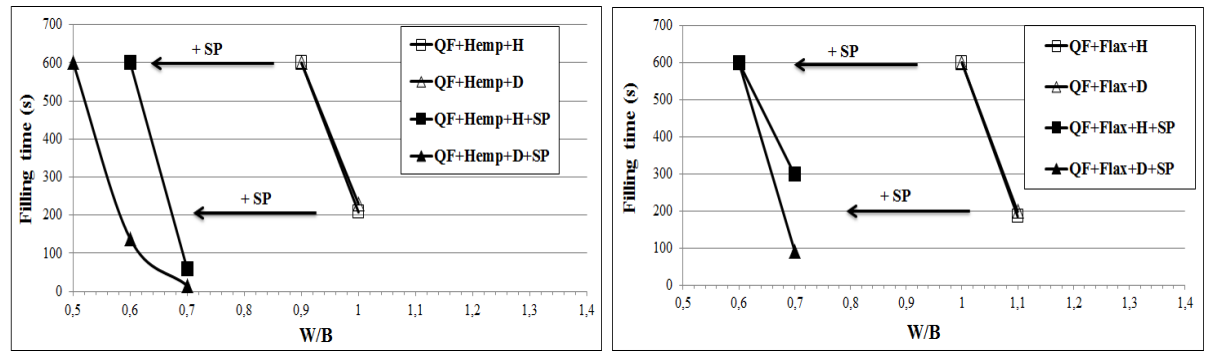

Figure 6: Filling times for mixtures including hemp straw (left) or flax straw (right).

Three prismatic specimens of $7 \times 7 \times 28 \mathrm{~cm}^{3}$ per formulation had been manufactured with the same wet density. These specimens were stored at ambient conditions at $20 \pm 2^{\circ} \mathrm{C}$ and $50 \pm 5 \% \mathrm{RH}$. The observations during the drying period have shown a proliferation of molds over the specimens. These molds could be caused by the lack of ventilation in the storage piece and the high water content. Moreover mixtures have a $\mathrm{pH}$ about of 8 , which is a favorite environment to develop the microorganisms. However, according to several studies [1, 30, 31 microbial proliferation can sometimes be observed on earth/plant or concretes/plant materials of construction. the choice was to use a lime to stop the proliferation of molds. The lime, in sufficient percentage, allows to increase the $\mathrm{pH}$ of mixtures. 


\subsubsection{Influence of lime on mixtures consistency}

A part of quarry fines has been substituted by lime in each mixture according to several percentages of lime $(1,5,10$ and $30 \%)$. These four percentages have been chosen to determine the optimal percentage of lime which can prevent mold growth. The lime is mixed with the QF previously then they are incorporated in the mixture. The letter $(\mathrm{L})$ has been added at the end of each mixture including a lime.

The consistency tests done with these mixtures have shown similar filling times for mixtures with or without lime. Adding lime to earth/plant mixtures induces an increase of mixtures pH up to 12 for $30 \%$ of lime.

\subsection{Manufacturing and observations}

After manufacturing, specimens were stored at the same conditions of $20 \pm$ $2^{\circ} \mathrm{C}$ and $50 \pm 5 \% \mathrm{RH}$. Figure 7 presents water content as a function of drying time for some mixes. This figure shows that all specimens had the same drying speed. The masses are stabilized at less than $1 \%$ after two weeks. Specimens have between 1.5 to $3 \%$ water content when mechanical tests were performed.

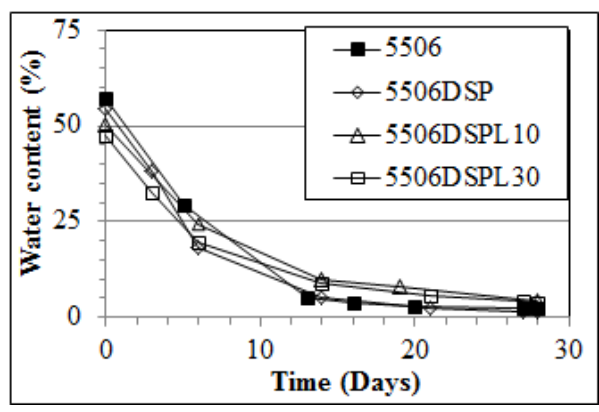

Figure 7: Water content as a function of drying time for some mixtures.

The macro-observations on specimens have shown that specimens including more than $10 \%$ and $30 \%$ of lime do not present molds. Therefore, only results 
obtained with both of these percentages (10 and 30\%) will be presented.

Figure 8 shows apparent density 28 days after manufacturing the studied specimens. The values were comprised between 780 and $900 \mathrm{~kg} / \mathrm{m}^{3}$ for specimens with hemp while with flax they were between 850 and $1000 \mathrm{~kg} / \mathrm{m}^{3}$ except for 5506DSP-F.

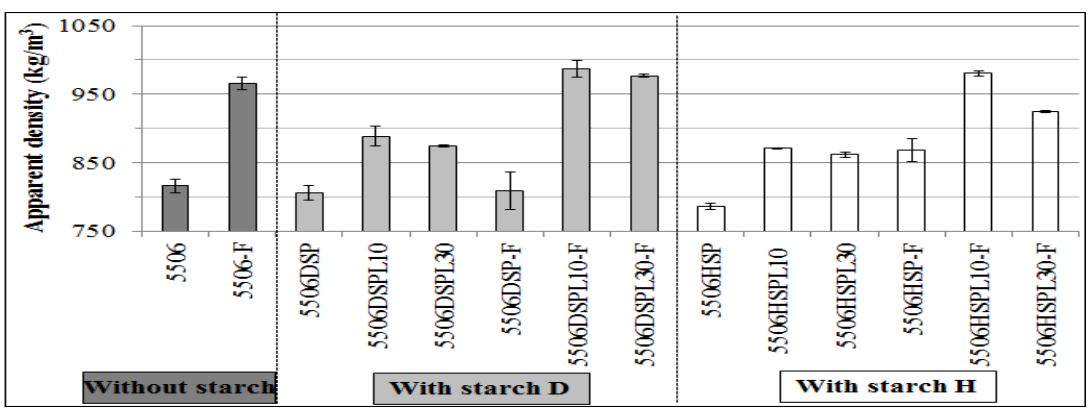

Figure 8: Apparent density of specimens $(7 \times 7 \times 28)$ just before the mechanical test.

\subsection{Results at hardened state}

The mechanical results have been divided in two parts: first one for mechanical results at laboratory samples scale and second one for the study at real scale.

\subsubsection{Mechanical results conducted with laboratory specimens}

Mechanical tests were done on specimens with $\mathrm{QF} / \mathrm{hemp}$ or flax straw + starch + superplasticizer +10 or $30 \%$ of lime. Flexural strength results presented in fig 9 show that:

- Adding starch to $\mathrm{QF} /$ hemp or flax straw mixtures enhances their flexural strengths which may be linked to the adhesion force between starch and QF particles according to previous research works [17. 
- The addition of lime causes an increase in the apparent densities of specimens due to its higher dry density $\left(2100 \mathrm{~kg} / \mathrm{m}^{3}\right)$ than that of the FAC

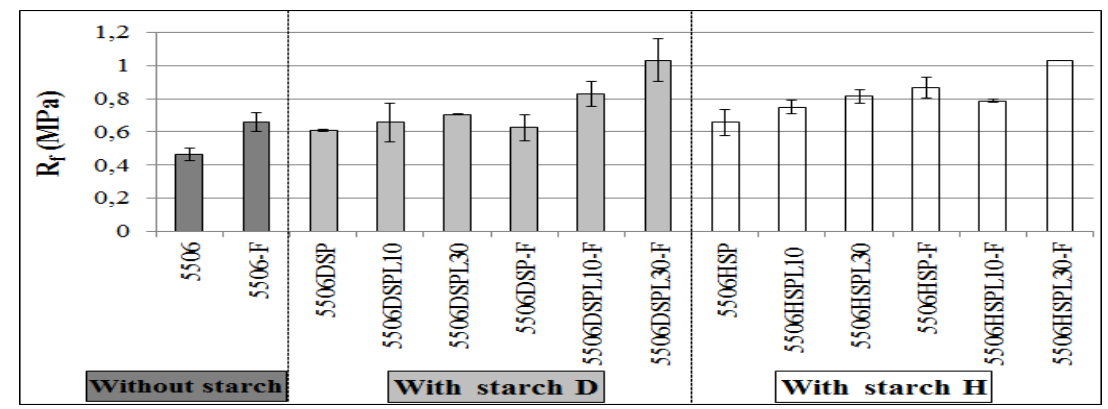

Figure 9: Flexural strength of specimens $\left(7 \times 7 \times 28 \mathrm{~cm}^{3}\right) 28$ days after manufacturing

The presence of plant in earth specimens avoids a sudden rupture, which means that specimen passes from a fragile behavior to an almost ductile behavior (Fig. 10). Perrot et al were observed a similar behavior on their samples [32].

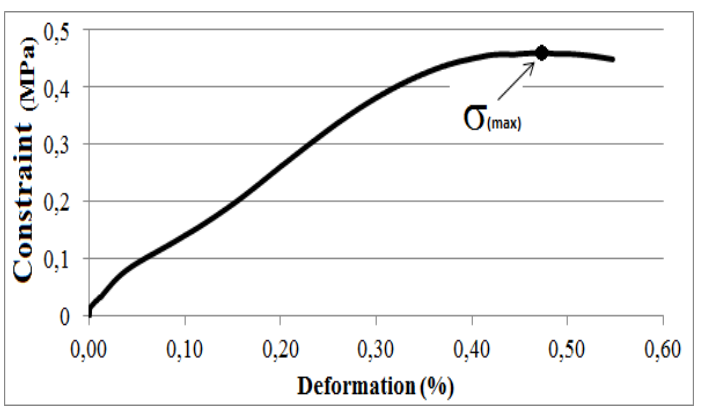

Figure 10: Flexural strength . 
In order to verify the influence of hemp and flax straws on these mixtures, the

355 weight. Therefore, the binder/aggregate ratio $(\mathrm{B} / \mathrm{A})$ has been decreased to 3.5. This step aims to study the effect of density on the mechanical strengths. For that purpose, three specimens per formulation were manufactured with the same wet density. The increase in the proportion of vegetable aggregates in these mixtures lead us to increase the water content. The percentage of lime is chosen as $30 \%$ of binder part which gives a best cohesion between binder and aggregates.

By following the same process of manufacturing, the drying time was similar for all specimens and the masses were stable after 2 weeks. Apparent masses measured before mechanical test are presented in figure 11. Apparent masses for these specimens were included between 450 and $600 \mathrm{~kg} / \mathrm{m}^{3}$.

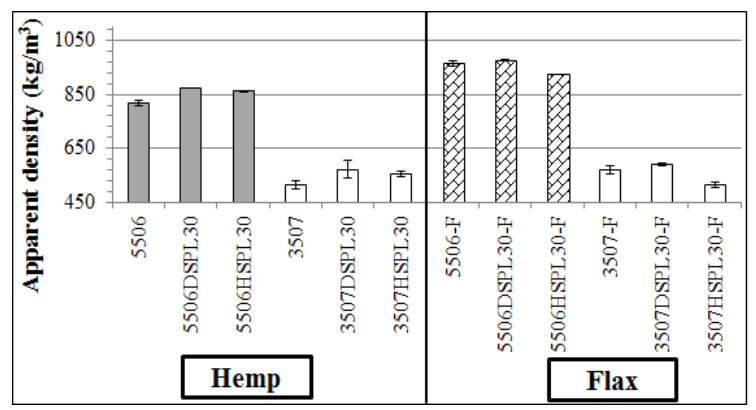

Figure 11: Apparent density of specimens $\left(7 \times 7 \times 28 \mathrm{~cm}^{3}\right)$ with $(\mathrm{B} / \mathrm{A}=3.5$ and 5.5$)$.

Flexural strength results obtained with these specimens are presented on figure 12. These results show that:

- The increase in the proportion of aggregates has a negative effect on flexural strengths. Flexural strengths obtained are included between 0.07 and $0.5 \mathrm{MPa}$ with a decrease up to $75 \%$ for the refered specimens and between (30 to $50 \%$ ) for specimens including starch, lime and superplasticizer. 
- Adding starch D or $\mathrm{H}+$ superplasticizer + lime increases flexural strengths which may be linked to the presence of starch according to previous research works [17.

- Starch D gives best resistances with both of hemp and flax straw specimens, which may be linked to its higher density in comparison with specimens including the other starch.

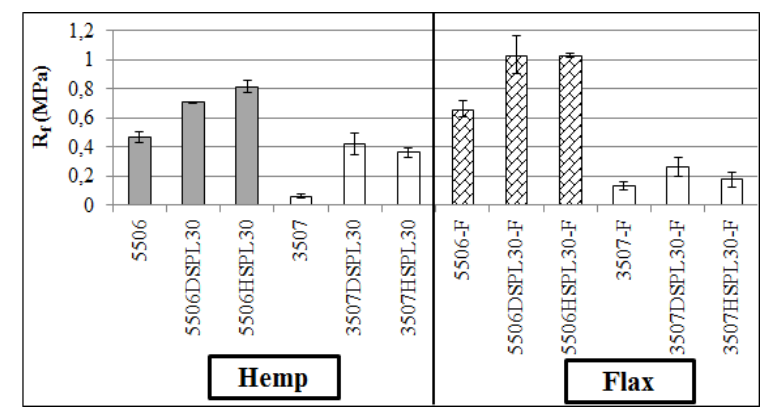

Figure 12: Flexural strength of specimens $\left(7 \times 7 \times 28 \mathrm{~cm}^{3}\right)$ with $(\mathrm{B} / \mathrm{A}=3.5$ and 5.5$) 28$ days after manufacturing.

\subsubsection{Mechanical results on blocks}

In order to verify the results obtained with the laboratory specimens, series of blocks $\left(50 \times 65 \times 7 \mathrm{~cm}^{3}\right)$ have been manufactured in following the same protocols than for laboratory specimens. The tile dimensions are chosen to be comparable with those already marketed like gypsum block or cellular concrete. Two blocks has been manufactured for each formulation with the same wet density, under two layers manually compacted. Blocks were unmolded immediately and stored under the conditions of $20 \pm 2^{\circ} \mathrm{C}$ and $50 \pm 5 \% \mathrm{RH}$.

After 28 days of storage, apparent density has been measured and mechanical tests had been done on all blocks. The target load for blocks is the same that required by European standard for plaster blocks [25] $\left(R_{f}=0.78 \mathrm{MPa}\right)$.

Figure 13 shows apparent density 28 days after manufacturing. The addition of 
lime causes an increase in the apparent densities of specimens due to its higher dry density $\left(2100 \mathrm{~kg} / \mathrm{m}^{3}\right)$ than that of the FAC $\left(1860 \mathrm{~kg} / \mathrm{m}^{3}\right)$.

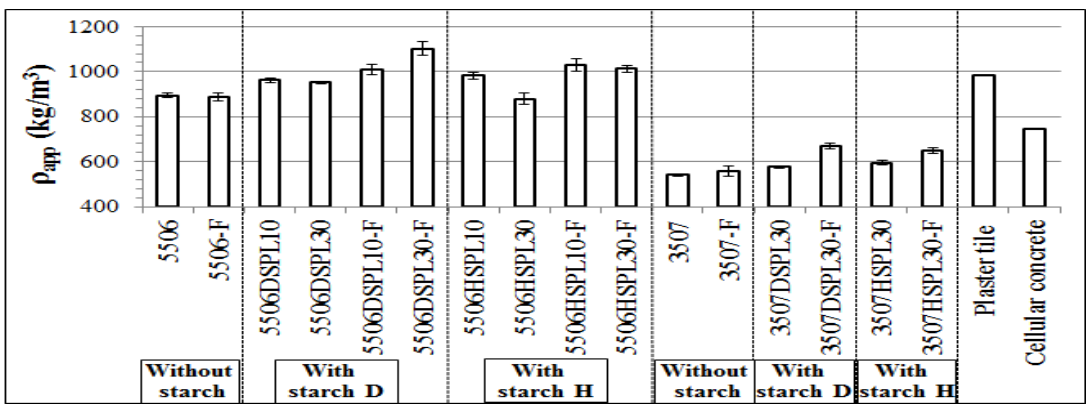

Figure 13: Apparent densities of blocks $\left(50 \times 65 \times 7 \mathrm{~cm}^{3}\right) 28$ days after manufacturing.

Figures 14 and 15 show flexural strength $\left(R_{f}\right)$ and compressive strength $\left(f_{c}\right)$ of studied blocks with hemp and flax straw. Mechanical tests at real scale show that :

- Studied blocks have also ductile behaviors at the rupture.

- Starch D gives best resistances with both of hemp and flax straw blocks. Blocks made with $\mathrm{B} / \mathrm{A}=5.5$, including $\mathrm{QF}(70 \%)$, hemp or flax straw, starch, SP and lime (30\%), reach the required flexural strengths for plaster blocks $(0.78 \mathrm{MPa})$ and give a higher resistance than that of cellular concrete.

- With a lime proportion of $30 \%$, flexural strengths increase widely in comparison with blocks including $10 \%$ at a similar apparent density.

- Blocks made with $\mathrm{B} / \mathrm{A}=3.5$ have a low resistance but efficient to support 


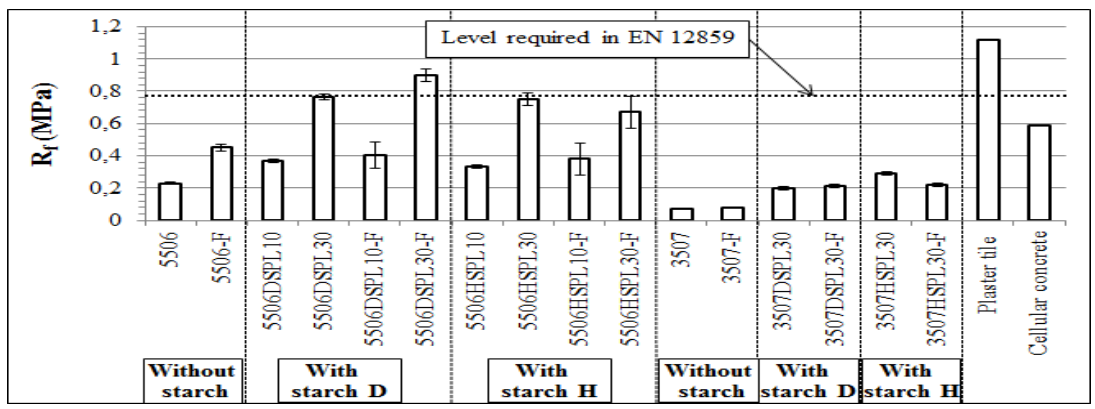

Figure 14: Flexural strength of blocks $\left(50 \times 65 \times 7 \mathrm{~cm}^{3}\right) 28$ days after manufacturing.

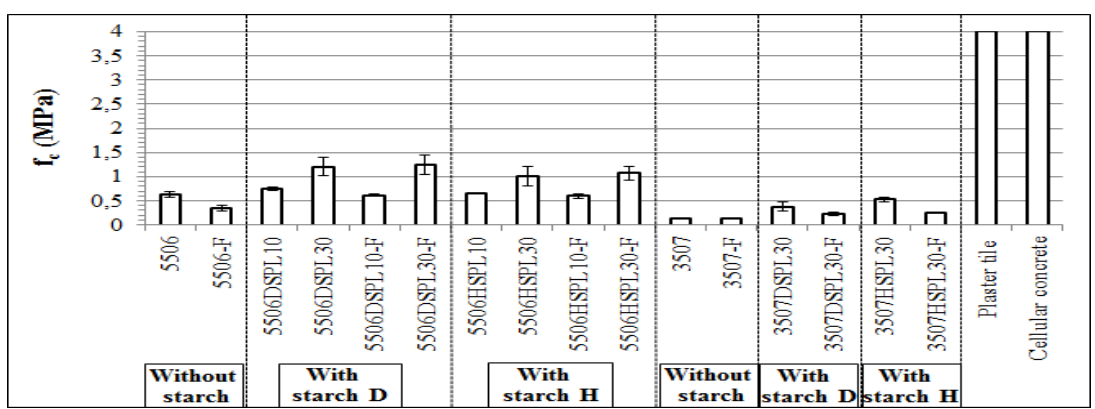

Figure 15: Compressive strength of blocks $\left(50 \times 65 \times 7 \mathrm{~cm}^{3}\right) 28$ days after manufacturing.

\subsubsection{Relation between flexural strength and apparent density}

To verify the correlation between results, figure 16 shows the evolution of flexural strengths according to apparent density of all the studied mixtures. Treatment of these results allows us to put studied formulations in two groups first one for $\mathrm{QF} /$ plant specimens and the second one for $\mathrm{QF} /$ plant with starch, superplasticizer and lime. Both of them follow an empirical law with polynomial form:

$$
R_{f}=a \times \rho_{a p p}^{2}-b \times \rho_{a p p}
$$

These two groups have the same coefficient (a) but a different coefficient (b).

$$
\text { Mixtures without starch: } R_{f}=1.1 E^{-6} \times \rho_{a p p}^{2}-4 E^{-4} \times \rho_{a p p}
$$


Mixtures with starch: $R_{f}=1.1 E^{-6} \times \rho_{a p p}^{2}-5 E^{-5} \times \rho_{a p p}$

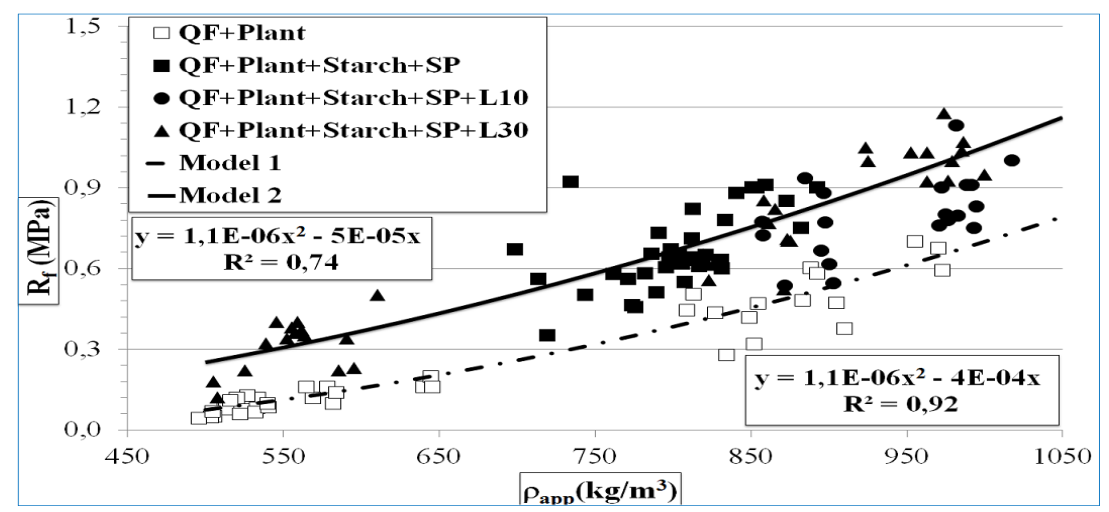

Figure 16: Relation between flexural strength and apparent density.

This equation allows us to target a level of resistance according to the chosen density.

\subsection{Thermal and acoustic insulation results}

Several mixes described in the previous section were tested. The particles of hemp and flax straw were also tested alone. Figure 17 shows a comparison between thermal characteristics of tested samples with other products like gypsum block and cellular concrete (CC), tested in laboratory, and compressed earth block (CEB) tested by Flament [26. In this figure, mentionned samples $35,35-\mathrm{F}, 55$ and $55-\mathrm{F}$ show an average of thermal values for formulations with or without starch, superplasticizer and lime (3 samples per formulation). Thermal results presented in figure 17 show that:

- The presence of starch, superplasticizer and/or lime has negligible influence on thermal results.

- The particles of hemp and flax straw have a similar thermal behavior with a thermal conductivity of about $0.06\left(\mathrm{~W} \times m^{-1} \times K^{-1}\right)$ and a specific 
heat capacity close to $13500\left(\mathrm{~J} \times m^{-2} \times K^{-1}\right)$.

- The thermal conductivity of CEB decreased by about $50 \%$ and $75 \%$ with the addition of 18 and $28 \%$, respectively, of plant particles (hemp or flax straw). This improvement of thermal insulation demonstrates the interest of studying earth/plant products.

- The association $\mathrm{QF} /$ hemp or flax straw (with $\mathrm{B} / \mathrm{A}=5.5$ ) gives a product with a better thermal conductivity (about $0.22 \mathrm{~W} \times m^{-1} \times K^{-1}$ ) than that of a gypsum block (about $0.32 \mathrm{~W} \times m^{-1} \times K^{-1}$ ) and close to that of a cellular concrete (about $0.19 \mathrm{~W} \times m^{-1} \times K^{-1}$ ).

- The thermal results of studied formulations (with $\mathrm{B} / \mathrm{A}=5.5$ ) are better than those of gypsum blocks with the same density. Furthermore, samples (with $\mathrm{B} / \mathrm{A}=3.5)$ give a better thermal conductivity about $0.12\left(\mathrm{~W} \times m^{-1}\right.$ $\left.\times K^{-1}\right)$ and a specific heat capacity close to $30000\left(\mathrm{~J} \times m^{-2} \times K^{-1}\right)$.

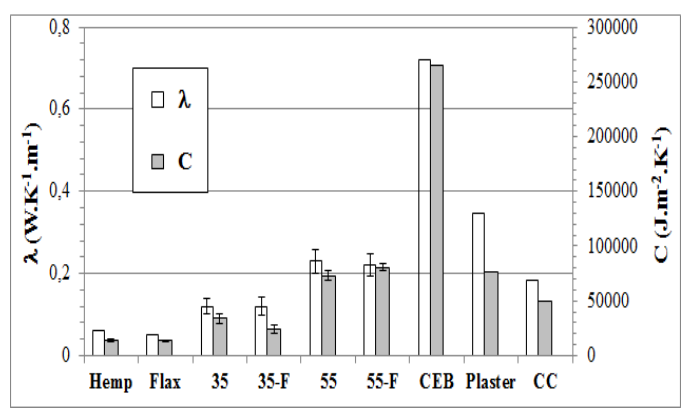

Figure 17: Thermal characteristics of studied samples.

For acoustic measurements, it was impossible to do acoustic test on hemp or flax straw alone with the same protocl than QF/plant samples. Figure 18 presents a comparison between acoustic absorption coefficients of studied samples with both of $\mathrm{B} / \mathrm{A}=3.5$ and 5.5 . 


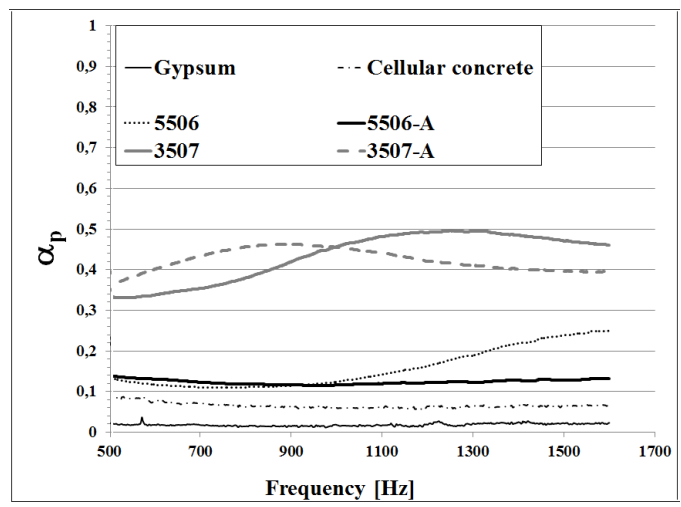

Figure 18: Acoustic absorption coefficient of studied samples.

Results show that an increase in the plant proportion in samples from 18 to $28 \%$ enhances about three to four times the acoustic absorption coefficient. Samples with $\mathrm{B} / \mathrm{A}=3.5$ give a good acoustic absorption for medium and high sound emissions. However, developed formulations (with $\mathrm{B} / \mathrm{A}=3.5$ and 5.5) give better acoustic absorption than that of a gypsum block and a cellular concrete block, which could be justify by the porosity of plant particles. It should be noted that the state of samples surface (flat, smooth, presence of voids, etc.) plays a very important role on the results of acoustic measurements, especially at low frequencies.

\section{Conclusion}

In this research, several formulations have been studied to evaluate the influence of starch on the properties of $\mathrm{QF} /$ hemp or flax straw materials. The results of this work could be concluded as follows:

- Adding starch to $\mathrm{QF} /$ hemp or flax straw mixtures increases their W/B ratio and improves its implementation which allows an unmolding immediate. Whereas, adding lime with sufficient percentage seems to give a 
better cohesion between binder and plant particles especially with the decrease of $\mathrm{B} / \mathrm{A}$ ratio and it is interesting to do additional tests to confirm this phenomenon.

- Adding both of studied starches (D or H) increases flexural and compressive strengths of $\mathrm{QF} / \mathrm{hemp}$ or flax straw samples.

- The presence of lime from $10 \%$ allows to stop the proliferation of moulds on studied specimens.

- Several studied blocks based on QF/lime $(70 / 30)+$ hemp or flax straw + starch $\mathrm{D}$ or $\mathrm{H}+$ superplasticizer (with $\mathrm{B} / \mathrm{A}=5.5$ ) reach the recommended flexural strength for gypsum block and exceed that of cellular concrete.

- The study of the relation between flexural strength and density has shown that tested specimens follow an empirical law with polynomial form.

- Thermal and acoustic measurements have shown a similar behaviour between $\mathrm{QF} /$ hemp straw and QF/flax straw. Studied samples made with $\mathrm{B} / \mathrm{A}=3.5$ give good performances of insulation.

\section{Acknowledge}

The authors would like to thank the company Carrières du Boulonnais, Roquette society, AKTA and Sika for sending the materials to the lab and enlightening the discussions on the project results.

The authors also thank Jérôme Lefebvre, Emmanuel Antczak, Philippe Herin, researchers at University of Artois, for their contribution in thermo-acoustic tests. 


\section{References}

${ }_{485}$ [1] V. Dubois, E. Wirquin, C. Flament, P. Sloma, Fresh and hardened state properties of hemp concrete made up of a large proportion of quarry fines for the production of blocks, Construction and Building Materials 102 (2016) $84-93$.

[2] Y. Brouard, N. Belayachi, D. Hoxha, N. Ranganathan, S. Mo, Mechanical and hygrothermal behavior of clay sunflower (helianthus annuus) and rape straw (brassica napus) plaster bio-composites for building insulation, Construction and Building Materials 161 (2018) 196 - 207. doi:https: //doi.org/10.1016/j.conbuildmat.2017.11.140

q [3] M. Degrave-Lemeurs, P. Gl, A. H. de Menibus, Acoustical properties of 495 hemp concretes for buildings thermal insulation: Application to clay and lime binders, Construction and Building Materials 160 (2018) 462 - 474. doi:https://doi.org/10.1016/j.conbuildmat.2017.11.064. URL http://www.sciencedirect.com/science/article/pii/ S0950061817322419

[4] A. Laborel-Prneron, J. Aubert, C. Magniont, C. Tribout, A. Bertron, 1. Plant aggregates and fibers in earth construction materials: A review, Construction and Building Materials 111 (2016) 719 - 734. doi:https://doi.org/10.1016/j.conbuildmat.2016.02.119.

URL http://www.sciencedirect.com/science/article/pii/ $505 \quad$ S0950061816301805

q [5] B. Mazhoud, F. Collet, S. Pretot, C. Lanos, Mechanical properties of hemp-clay and hemp stabilized clay composites, Construc-

口 tion and Building Materials 155 (2017) 1126 - 1137 doi:https: //doi.org/10.1016/j.conbuildmat.2017.08.121. 
URL

http://www.sciencedirect.com/science/article/pii/

S0950061817317282

[6] G. Araya-Letelier, J. Concha-Riedel, F. Antico, C. Valds, G. Cceres, Influ-

a ence of natural fiber dosage and length on adobe mixes damage-mechanical behavior, Construction and Building Materials 174 (2018) 645 - 655. doi:https://doi.org/10.1016/j.conbuildmat.2018.04.151. URL http://www.sciencedirect.com/science/article/pii/ S0950061818309589

q [7] K. E. Azhary, Y. Chihab, M. Mansour, N. Laaroussi, M. Garoum, Energy efficiency and thermal properties of the composite material clay-straw, Energy Procedia 141 (2017) 160 - 164, power and Energy Systems Engineering. doi:https://doi.org/10.1016/j.egypro.2017.11.030. URL http://www.sciencedirect.com/science/article/pii/ S187661021735436X

[8] M. Labat, C. Magniont, N. Oudhof, J.-E. Aubert, From the ex525 perimental characterization of the hygrothermal properties of n. straw-clay mixtures to the numerical assessment of their buffering potential, Building and Environment 97 (2016) $69 \quad-81$. doi:https://doi.org/10.1016/j.buildenv.2015.12.004

(u) URL http://wWW.sciencedirect.com/science/article/pii/ S0360132315302018

[9] D. M. Andres, D. L. Manea, R. Fechete, E. Jumate, Clay mora tar performance improvement by modifying the physical characteristics of wheat straw Procedia Technology 22 (2016) 335 342, 9th International Conference Interdisciplinarity in Engineering, INTER-ENG 2015, 8-9 October 2015, Tirgu Mures, Romania. 
doi:https://doi.org/10.1016/j.protcy.2016.01.106

URL http://www.sciencedirect.com/science/article/pii/

S2212017316001079

[10] D. M. Andres, D. L. Manea, R. Fechete, E. Jumate, Green plastering mortars based on clay and wheat straw, Procedia Technology 22 (2016) 327 - 334, 9th International Conference Interdisciplinarity in Engineering, INTER-ENG 2015, 8-9 October 2015, Tirgu Mures, Romania. doi:https://doi.org/10.1016/j.protcy.2016.01.105 URL http://www.sciencedirect.com/science/article/pii/

[11] L. Aouba, C. Bories, M. Coutand, B. Perrin, H. Lemercier, Properties of

1. fired clay bricks with incorporated biomasses: Cases of olive stone flour and wheat straw residues, Construction and Building Materials 102 (2016) 7 - 13. doi:https://doi.org/10.1016/j.conbuildmat.2015.10.040. URL http://www.sciencedirect.com/science/article/pii/ S0950061815304517

[12] W. Schmidt, H. J. H. Brouwers, H.-C. Kuhne, B. Meng, Enhance the rheological and mechanical properties of clayey materials by adding starches, Applied Rheology. 23 (5) (2013) 12. tal investigation on the mechanical performance of starchhemp composite materials, Construction and Building Materials 61 (2014) 106 - 113. doi:https://doi.org/10.1016/j.conbuildmat.2014.01.084.

[14] A. Le, A. Gacoin, A. Li, T. Mai, N. E. Wakil, Influence of various starch/hemp mixtures on mechanical and acoustical behavior of starch- 
hemp composite materials, Composites Part B: Engineering 75 (2015) 201

- 211. doi:https://doi.org/10.1016/j.compositesb.2015.01.038.

[15] A. Akindehinde, W. Schmidt, E. Iyukes, The influence of starches on some properties of concretes, Proceedings in Advances in Cement and Concrete Technology in Africa.2015.

[16] L. Crépy, J.-Y. Petit, E. Wirquin, P. Martin, N. Joly, Synthesis and evaluation of starch-based polymers as potential dispersants in cement pastes and self leveling compounds, Cement and Concrete Composites 45 (2014) 29 - 38. doi:https://doi.org/10.1016/j.cemconcomp.2013.09.004

[17] G. Alhaik, M. Ferreira, V. Dubois, E. Wirquin, S. Tilloy, E. Monflier, G. Aouad, Enhance the rheological and mechanical properties of clayey materials by adding starches, Construction and Building Materials 139 (2017) $602-610$.

[18] AFNOR, Aggregates for concrete, EN 12620 (2008).

[19] AFNOR, Non-destructive testing - X-ray diffraction from polycrystalline and amorphous material - Part 2: procedures. EN 13925-2 (2003).

[20] A. Buléon, P. Colonna, V. Planchot, S. Ball, Starch granules : structure and biosynthesis., International Journal of Biological Macromolecules. 23 (1998) 85-112.

[21] S. Amziane, F. Collet, M. Lawrence, C. Magniont, V. Picandet, M. Sonebi, a Recommendation of the rilem tc 236-bbm: characterisation testing of hemp

nhiv to determine the initial water content, water absorption, dry density, particle size distribution and thermal conductivity, Materials and Structures 50 (3) (2017) 167. doi:10.1617/s11527-017-1029-3.

URL https://doi .org/10.1617/s11527-017-1029-3 
[22] AFNOR, NF EN 196-1: Méthodes d'essais des ciments - Partie 1: détermination des résistances mécaniques (2006).

[23] AFNOR, Testing fresh concrete - Part 3: Vebe test. EN 12350-3 (2012).

[24] AFNOR, Testing hardened concrete - Part 5: flexural strength of test specimens. EN 12390-5 (2012).

[25] AFNOR, Gypsum blocks: Definitions, requirements and test methods. NF EN 12859 (2011).

[26] C. Flament, Valorisation des fines de lavage de granulats : application à la construction en terre crue, Ph.D. thesis, University of Artois (2013. [in French]).

[27] V. CEREZO, Proprits mcaniques, thermiques et acoustiques d'un matriau base de particules vgtales : approche exprimentale et modlisation thorique, Ph.D. thesis, Lyon: Institut National des Sciences Appliques de Lyon (16 juin 2005. [in French]).

[28] AFNOR, Thermal performance of building materials and products - Determination of thermal resistance by means of guarded hot plate and heat flow meter methods Products of high and medium thermal resistance. EN 12667) (2001)

[29] AFNOR, Acoustics - Determination of sound absorption coefficient and impedance in impedance tubes - Part 2: Transfer-function method. EN ISO 10534-1 (2003).

[30] Rammed Earth Conservation, c. mileto and f. vegas and v. cristini. Edition, Taylor and Francis Group, 2012. 
[31] S. Marceau, P. Glé, M. Gueguen, E. Gourlay, S. Moscardelli, I. Nou, S. Amziane, L. Abdellaoui, Assessment of the durability of bio-based insulating materials., Proceedings in First International Conference on Biobased Building Materials (2015) 198-202.

[32] A. Perrot, D. Rangeard, F. Menasria, S. Guihneuf, Strategies a for optimizing the mechanical strengths of raw earth-based mor${ }_{615}$ tars Construction and Building Materials 167 (2018) 496 - 504. doi:https://doi.org/10.1016/j.conbuildmat.2018.02.055. URL http://www.sciencedirect.com/science/article/pii/ S0950061818302885 